\title{
The association between MGP gene polymorphisms and coronary artery disease
}

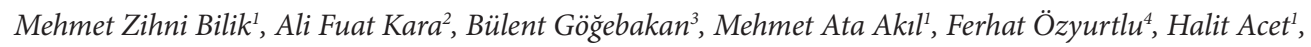
Sait Alan ${ }^{1}$

${ }^{1}$ Dicle University, Faculty of Medicine , Department of Cardiyology, Diyarbakır, Turkey

${ }^{2}$ Genesis Hospital, Department of Cardiyology, Diyarbakır, Turkey ${ }^{3}$ Mustafa Kemal University, Faculty of Medicine, Department of Medical Biology, Hatay, Turkey

${ }^{4}$ Grandmedical Hospital, Department of Cardiyology, Manisa, Turkey

\section{Correspondence:}

Dr. Mehmet Zihni Bilik, Dicle Üniversitesi Tip Fakültesi, Kardiyoloji Anabilim Dalı, Kalp Hastanesi, Diyarbakır, Türkiye
E-mail: mzbilik@mynet.com Received: 03 June 2016, Accepted: 13 July 2016 DOI: $10.5799 /$ jcei.328614

\section{INTRODUCTION}

Coronary artery disease (CAD) is one of the most common causes of mortality and morbidity in the world. The main cause of CAD is atherosclerosis [1].

Atherosclerosis affects most of the arterial system especially aorta, carotid, and coronary and cerebral arteries. Inflammation, endothelial injury, oxidative stress, and calcification are important in the pathogenesis of atherosclerosis [2]. Calcification is caused by calcium deposition in tissues [3]. In the coronary arterial plaques, calcium deposition makes an important contribution to the plaque volume [4]. Coronary artery calcification (CAC) has an important role in the formation of atherosclerosis and there is a strong relationship between CAC and plaque burden [5]. CAC is an active process.
It has been revealed that $\mathrm{CAC}$ is an independent factor for cardiovascular mortality and morbidity [6]. Clinically, CAC leads to stiffening of the arterial vessel wall and this leads to a reduction in arterial compliance. Thus, the perfusion in the coronary artery decreases as a result of fatal complications that arise $[7,8]$. CAC is commonly seen with aging, in patients with chronic kidney disease, diabetes mellitus, and atherosclerosis $[9,10]$.

Matrix Gla protein (MGP) is one of the protective proteins, which inhibit arterial calcification [11]. MGP contains 84 amino acids and molecular weight of mature MGP is $10-\mathrm{kDa}$ [12]. It has been shown that MGP deficient rat models have an excessive mineralization in the cartilage and severe calcification in the main arteries. As a result, vessel occlusion occured and the rats died within 8 weeks after they were born due to damage of the thoracic and abdominal 
aorta [11]. Normally, the vascular smooth muscle cells and chondrocytes have non-calcified extracellular matrix. However, it has been shown that both of them have severe calcification when MGP was deficient. According to the data, MGP was suggested to be a potent calcification inhibitor macromolecule [13].

In this study, we aimed to investigate the relationship between three single nucleotide polymorphisms of MPG (T-138C, G-7A and Thr83Ala) and CAD.

\section{METHODS}

\section{Patients}

The study included a total of 115 patients who were admitted to the cardiology department and underwent a coronary angiography between January 2009 and January 2010. Fifty eight patients with CAD (66\% male) were registered as the patient group, and 57 cases with normal coronary artery without CAD (53\% male) proven angiographically, were registered as control group. The study was approved by the Local Ethics Committee and informed consent was obtained from each patient.

All patients received a complete physical examination. Hypertension was defined as systolic blood pressure $\geq 140 \mathrm{mmHg}$, diastolic blood pressure $\geq 90 \mathrm{mmHg}$, or active use of antihypertensive medication. Diabetes mellitus (DM) was considered when fasting plasma glucose levels were above $126 \mathrm{mg} / \mathrm{dL}$ in at least two different measurements or active use of anti-diabetic drugs. Smoking was defined as currently smoking or ex-smokers who forwent smoking in the past 6 months. Patients with severe liver and renal diseases, heart failure, cancer, severe valvular diseases were excluded from the study. Blood was collected under sterile conditions into 5 $\mathrm{mL}$ tubes containing EDTA potassium salt as an anticoagulant (samples were frozen and stored at $-20^{\circ} \mathrm{C}$ ). Total cholesterol, HDL-cholesterol, and LDL-cholesterol were measured by an Abbott Architect C16000 autoanalyzer (Abbott Laboratory, Abbott Park, IL, USA) with original kits. Fasting lipid panels were obtained after an overnight fast.

Coronary angiography was routinely performed using the Allura Xper FD10 (Philips, Amsterdam, The Netherlands) through femoral artery by Judkins technique. The contrast agent was Iopamiro 370 (Bracco, Milan, Italy) that used in all patients. Coronary artery disease was defined as stenosis greater than $50.0 \%$ at least in one of the major coronary arteries. Transthoracic echocardiography was performed to determine left ventricular ejection fraction (LVEF) (Vivid S6, GE Medical Systems, USA).

\section{Statistical Analysis}

Statistical analysis was performed using statistical software package (SPSS 18.0, Chicago, USA). The quantitative parameters were reported as mean and standard deviation. The differences between groups were evaluated by student $\mathrm{t}$-, chi-square, and Fisher's Exact tests. A p-value of less than 0.05 was considered to be significant. The genotype frequencies for the polymorphisms were compared with under conditions of Hardy-Weinberg equilibrium using the chi-square test.

\section{DNA extraction and Genotyping}

Five milliliters of blood was collected into EDTA containing tubes to use for DNA isolation and blood was stored at $-20^{\circ} \mathrm{C}$. The genomic DNA was extracted from WBC using salting out method [14].

\section{DNA Analysis}

Polymerase Chain Reaction (PCR) technique was used for DNA analysis. Reproduction process of the relevant regions for MGP gene was performed by in-house type MJ Research PTC200 PCR machine.

\section{PCR Process}

Reference sequences were taken from NCBI database. For MGP structural gene region, gi:37543832 numbered sequence which is in the NT_009714 numbered contigs region, for promoter region, gi:3172535 numbered sequence, which is in the AF067176 accession numbered region were used to design the primers.

The base pairs which are used to analyze the MGP gene polymorphism were designed by using the online primer design program (http://workbench.sdsc.edu/).

Firstly, a gradient PCR was performed for 1 DNA sample and 3 base pairs to check the annealing temperature for the base pairs used in PCR. Optimized annealing temperature was obtained for T-138C and Thr83Ala as $59^{\circ} \mathrm{C}$ for G-7A as $65^{\circ} \mathrm{C}$.

PCR was performed in a total volume of $20 \mu \mathrm{L}$ of a buffer solution containing the following: distilled water $(13.9 \mu \mathrm{L}), 10 \mathrm{X}$ Taq buffer $(2.4 \mu \mathrm{L}), 25 \mathrm{mM} \mathrm{MgCl}_{2}(1.2 \mu \mathrm{L}), 2 \mathrm{mM}$ dNTP mix (1.6 $\mu \mathrm{L}), 100 \mathrm{mM}$ F-Primer $(0.16 \mu \mathrm{L}), 100 \mathrm{mM}$ R-Primer $(0.16 \mu \mathrm{L})$, Taq polimerase- $5 \mathrm{u} / \mu \mathrm{L}(0.08 \mu \mathrm{L})$, and genomic DNA $(0.5 \mu \mathrm{L})$.

For G-7A F-primer (5'-CTAGTTCAGTGCCAACCCTTCCCCACC-3') and the R-primer (5'-TAGCAGCAGTAGGGAGAGAGGCTCCCA-3').

For T-138C F-primer (5'-
AAGCATACGATGGCCAAAACTTCTGCA -3') and R-primer

\section{(5'- GAACTAGCATTGGAACTTTTCCCAACC-3').}

For Thr83Ala F-prime (5'-CACGAGCTCAATAGGGAAGC-3') and R-primer

\section{(5'- GCTGCTACAGGGGGATACAA- 3').}

PCR for three polymorphisms was run as following: Denaturation at $94^{\circ} \mathrm{C}$ for 5 -min followed by 35 cycles of $94^{\circ} \mathrm{C}$ for $30 \mathrm{~s}, 65^{\circ} \mathrm{C}$ (G-7A), and $59^{\circ} \mathrm{C}$ (Thr83Ala and T-138C) for $60 \mathrm{~s}$, and $72^{\circ} \mathrm{C}$ for $60 \mathrm{~s}$ and final extension at $7 \mathrm{~min}$.

Variables of the reaction except the primers' annealing temperature were same in all reactions and obtained products 
were analyzed by Restriction Fragment Length Polymorphism (RFLP).

\section{Agarose Gel Elektrophoresis}

Agarose gel electrophoresis was used to check the PCR reaction. Samples were run on agarose gel (1.0\%) for 40 minutes at 90 volts (range 37-501 bp) in the presence of pUC19 DNA/Mspl marker. Then it was visualized by UV transillumination after ethidium bromide staining.

\section{Restriction Process}

Ten $\mu$ PCR product was placed into microcentrifuge tube $(0.2 \mathrm{ml})$ along with distilled water $(\mathrm{dH} 2 \mathrm{O})(3.4 \mu \mathrm{l})$ and $10 \mathrm{X} \mathrm{RE}$ buffer $(1.5 \mu \mathrm{l})$ and RE [BseNI, HaeIII, NcoI $(10 \mathrm{u} / \mu \mathrm{l})$ ] to obtain a $0.1 \mu \mathrm{l}$ mixture. Five $\mu \mathrm{l}$ of a prepared mixture was added to each tube containing the PCR products. These were then subjected to restriction digestion. After incubation, samples were run on agarose gel (3.0\%) for 40 minutes at 90 volts (range 37-501 bp) in the presence of pUC19 DNA/Mspl marker for analyzing the restricted products. Subsequently, the digested DNA was visualized by UV transillumination by staining with ethidium bromide. The genotype of each sample was determined by analyzing the obtained bands.

\section{RFLP Process}

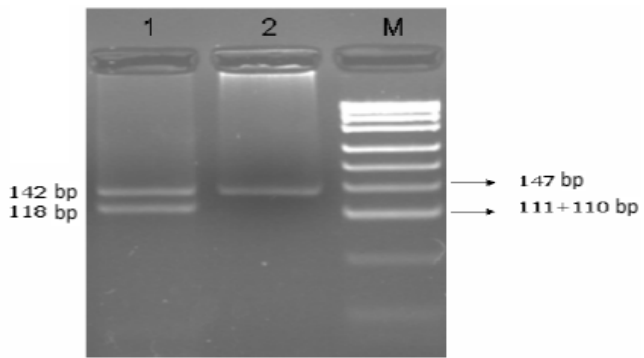

Figure 1. The band images of nucleotide exchange for T-138C polymorphism obtained by the RFLP method

By PCR, 142 bp sized product was obtained for T-138C. Then, it was restriction digested with BseNI and ran on an agarose gel using electrophoresis (3.0\%). The nucleotide was found in the -138. If the position was $C$, then BseNI cannot digest the $142 \mathrm{bp}$ fragment. If the nucleotide was $\mathrm{T}$, the enzyme performed the restriction digest. By the restriction process, 2 DNA fragments (118 and $24 \mathrm{bp}$ in length) were obtained. According to this, sample 1 was TC and 2 was CC. M was the pUC19 DNA/Mspl marker.

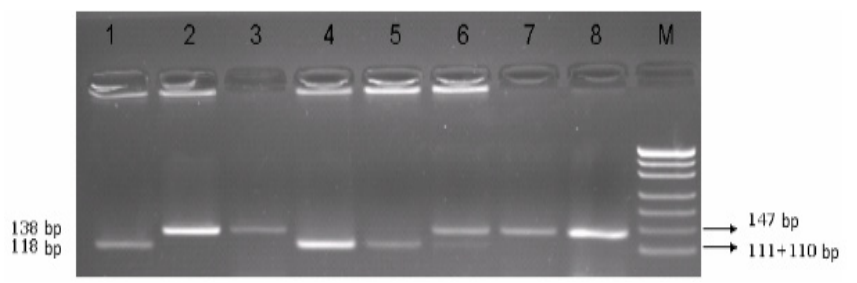

Figure 2. The band images of nucleotide exchange for G-7A polymorphism obtained by the RFLP method
By PCR, the 138 bp sized product was obtained for G-7A and subjected to NcoI restriction digestion. Samples were genotyped, and restriction digested products were run using agarose gel electrophoresis (3.0\%) in the presence of pUC19 DNA/Mspl marker. The nucleotide in the -7 position was $G$, if the NcoI enzyme did not digest the sample. If the nucleotide was A, the enzyme digested the DNA. By restriction process, 2 DNA fragments were obtained (118 and $20 \mathrm{bp}$ in length). According to this, samples 2, 3 and 7 are GG; samples 1,4 and 5 are AA; sample 6 was GA; and sample 8 is used as negative control.

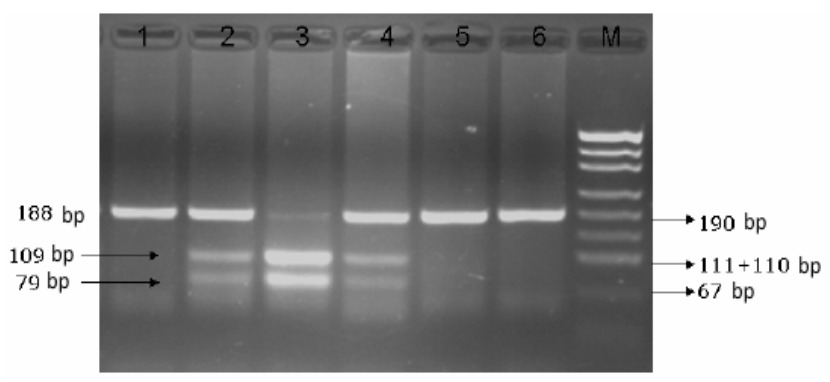

Figure 3. The band images of nucleotide exchange for Thr83Ala polymorphism $(A \rightarrow G)$ obtained by the RFLP method

By PCR, a 188 bp sized product was obtained for Thr83Ala. Then, it was restricted with HaeIII enzyme and was run on an agarose gel electrophoresis (3.0\%). If A, HaeIII did not digest the DNA. If the nucleotide was $\mathrm{G}$, the enzyme performed the restriction digestion. By the restriction process, 2 DNA fragments were obtained (109 and $79 \mathrm{bp}$ in length). According to this, samples 1 and 5 are AA; samples 2, 3 and 4 are GA; and sample 6 was a negative control. M was DNA marker (pUC19 Mspl).

\section{RESULTS}

The clinical characteristics of 58 patients with CAD and 57 controls were summarized in Table 1 . In the CAD group $66 \%$ of patients and in control group 53\% were male. The mean age was significantly $(\mathrm{p}=0.048)$ higher in CAD group $(63.6 \pm 12.3$ years $)$ than in the control ( $47.7 \pm 11.7$ years). There was no significant differences between the two groups with respect to LDL-C, HDL-C, total cholesterol, cigarette smoking, and LVEF. Diabetes mellitus $(p=0.012)$ and hypertension ( $p=0.032)$ were significantly more prevalent in the patient group.

Results of patient genotyping of the MGP genes were summarized in Table 2. As shown, TT, TC, and CC genotype distributions for $\mathrm{T}-138 \mathrm{C}$ polymorphism in CAD group were $39.7 \%, 37.9 \%$ and $22.4 \%$, respectively. In the control group, they were $42.1 \%$, $45.6 \%$, and $12.3 \%$, respectively. There was no statistically significant difference between groups ( $p=0.762$ for TC, $p=0.289$ for CC). T and $\mathrm{C}$ allele frequencies were not significant between controls and patients $(\mathrm{p}=0.326)$

GG, GA and AA genotype distributions for G-7A polymorphism were as following. In CAD group were $39.7 \%, 39.7 \%$ and $20.6 \%$ 
respectively. In the control group, they were $38.6 \%, 49.1 \%$ and $12.3 \%$, respectively. The difference between groups was not significant ( $\mathrm{p}=0.556$ for $\mathrm{GA}$ and $\mathrm{p}=0.422$ for $\mathrm{AA}$ ). The $\mathrm{G}$ and $\mathrm{A}$ allele frequencies were not significant $(\mathrm{p}=0.567)$.
AA, AG, and GG genotype distributions for Thr83Ala polymorphism also were not significant ( $\mathrm{p}=0.120$ for $\mathrm{AG}$ and $\mathrm{p}=0.777$ for GG). Distributions in CAD group were $36.2 \%, 46.6 \%$ and $17.2 \%$, respectively. In the control group, they were $24.6 \%$, $61.4 \%$ and $14.0 \%$, respectively. The A and G allele frequencies were not significant $(\mathrm{p}=0.518)$

Table 1. Baseline characteristics of the study population

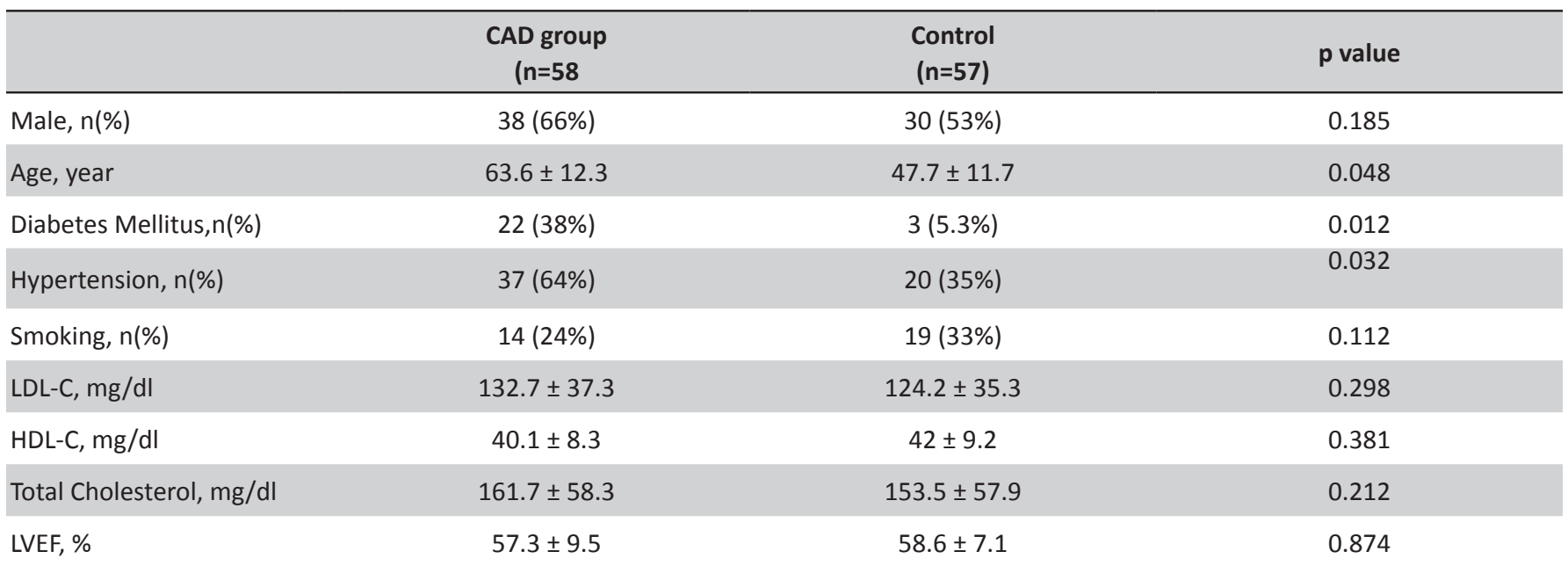

Data were presented as mean \pm SD or \%. CAD: coronary artery disease, HDL-C: high density lipoprotein cholesterol, LDL-C: low density lipoprotein cholesterol, LVEF: left ventricular ejection fraction.

Table 2. The distribution of genotypes and alleles in CAD and control groups for T-138C, G-7A and Thr83Ala (4A-G) polymorphisms

\begin{tabular}{|c|c|c|c|c|}
\hline $\begin{array}{l}\text { Genotypes } \\
\text { MGP } 138 \text { (T-C) }\end{array}$ & $\begin{array}{c}\text { CAD } \\
(n=58), n(\%)\end{array}$ & $\begin{array}{c}\text { Control } \\
(n=57), n(\%)\end{array}$ & $\mathbf{P}$ & OR $(95 \% \mathrm{Cl})$ \\
\hline$T / T$ & $23(39.7)$ & $24(42.1)$ & & \\
\hline $\mathrm{T} / \mathrm{C}$ & $22(37.9)$ & $26(45.6)$ & $0.762^{+}$ & $0.883(0.394-1.977)$ \\
\hline $\mathrm{C} / \mathrm{C}$ & $13(22.4)$ & $7(12.3)$ & $0.289^{*}$ & $1.938(0.656-5.721)$ \\
\hline \multicolumn{5}{|l|}{ Alleles } \\
\hline $\mathbf{T}$ & $68(58.6)$ & $74(64.9)$ & & \\
\hline \multicolumn{5}{|l|}{ Genotypes } \\
\hline \multicolumn{5}{|l|}{ MGP 7 (G-A) } \\
\hline G/G & $23(39.7)$ & $22(38.6)$ & & \\
\hline G/A & $23(39.7)$ & $28(49.1)$ & $0.556+$ & $0.786(0.352-1.755)$ \\
\hline A/A & $12(20.6)$ & $7(12.3)$ & $0.422^{*}$ & $1.640(0.546-4.929)$ \\
\hline \multicolumn{5}{|l|}{ MGP 4 (A-G) } \\
\hline$A / A$ & $21(36.2)$ & $14(24.6)$ & & \\
\hline$A / G$ & $27(46.6)$ & $35(61.4)$ & $0.120+$ & $0.514(0.222-1.194)$ \\
\hline G/G & $10(17.2)$ & $8(14.0)$ & $0.777^{*}$ & $0.833(0.264-2.632)$ \\
\hline \multicolumn{5}{|l|}{ Alleles } \\
\hline A & 69 (59.5) & $63(55.3)$ & & \\
\hline G & $47(40.5)$ & $51(44.7)$ & $0.518+$ & $0.841(0.499-1.420)$ \\
\hline
\end{tabular}

OR: Odds ratio, $\mathrm{Cl}$ : Confidence interval, ${ }^{+}$Chi-square test, ${ }^{*}$ Fisher's Exact Test 


\section{DISCUSSION}

Atherosclerosis is the major cause of CAD, and is characterized by endotelial dysfunction, vascular inflammation, calcification, and accumulation of lipid and inflammatory cells in the intima [1]. In the development and progression of atherosclerosis, genetic risk factors can play an important role especially in young patients adding to classic risk factors such as hypertension, hyperlipidemia, smoking, and diabetes mellitus [15]. Some of the patients with CAD are come up with acute myocardial infarction or sudden cardiac death without any pre-specified symptoms. At this point, determination of the risk profile for cardiovascular disease and the initiation of appropriate prevention programs for patients before symptoms are highly important.

At present, frequently used protection algorithms including classic cardiovascular risk factors may be inadequate to determine the person's risk profile. Recently some methods such as coronary artery calcium scoring are thought to be helpful in this regard. Coronary artery calcification by computed tomography scan is a noninvasive measure of the extent of atherosclerosis. CAC progression is strongly associated with most CAD risk factors [16]. There is a relationship between coronary arterial calcification and CAD [17]. CAC burden is a major determinant of subclinical atherosclerosis and gives prognostic information, which adds to the conventional risk factors about a person's cardiovascular risk. After it has been demonstrated that CAC is a reversible process [18], attention to arterial calcification inhibitors was increased.

One of the major calcification inhibitors is MGP. Although the molecular mechanism of MGP function is not fully understood, the firstly collected information has revealed that its major role was the inhibition of soft tissue calcification. The first data about this effect of MGP has come from a study which rats were treated with warfarin an antagonist of the K-vitamin [19]. Massive cartilage calcification was developed especially in epiphysis and facial bones in rats [20]. After MGP has been identified in cartilage, the cartilage calcification was thought to be associated with the loss of MGP function [21]. The primary function of MGP was found to inhibit arterial media calcification. MGP-knockout rats died within 6-8 weeks due to main artery rupture and resulted in elastic lamellae calcification in the tunica media [22].

In MGP knockout rats, calcium-phosphate deposition ratios were similar to hydroxyapatite in arterial calcification-like bone mineralization. By histochemical studies, it has been shown that arterial calcification was together with change of vascular smooth muscle cells to chondrocyte-like cells [19]. MGP inhibits the conversion of vascular muscle cells to chondrocyte and osteoblastlike cells. This finding was also observed by Shanahan et al. They reported that MGP expression in normal vessels was less than in diabetic patient's vessel media with presenting Mönckeberg sclerosis [18].

In normal vessels, MGP synthesis is low because the inhibition of calcification is less needed. In calcified vessels, there was increased MGP values by MGP synthesis. But, it has been shown that increased MGP containing mostly an inactive form of MGP (uncarboxylated MGP-ucMGP) [18]. ucMGP accumulate in atherosclerotic and calcified arteries. Carboxylated MGP (cMGP) is the active form of MGP and it is usually not presenting in calcified arteries. Sweat et al. reported that calcified arterial lesions in rats were included high MGP values and this MGP form was ucMGP [23]. Another study showed massive ucMGP around calcified lesions in rat's arteries which were treated with warfarin [18].

CAC is an important predictor of cardiovascular mortality and recent data present that MGP is a major calcification inhibitor. Although it is known CAC's this affect, Huang et al. showed that massive coronary arteries calcification was not associated with plaque stress [24].

In vitro and clinical studies had been performed about MGP gene polymorphism have different or opposite results. FerzanehFar et al. reported that $-138 \mathrm{C}$ molecular variety was more effective than -138T up to 4 times in an expression study by using vascular smooth muscle cells in rats. In this study -138CC homozygotes had 30\% higher serum MGP values. Therefore, they considered that the $-138 \mathrm{C}$ allele could provide protection against tissue calcification. And indicated that in vitro G-7A allele did not lead to significant differences in the expression of gene [25]. On the other hand, Hermann et al. reported that the minor $-138 \mathrm{C}$ allele was decreased and the promoter regio activity was $20 \%$ in rats' vascular smooth muscle cells and 50\% in human fibroblast cell line when compared with the $-138 \mathrm{~T}$ allele. The G-7A allele were more common in patients with previous myocardial infarction, and the $-7 \mathrm{~A}$ allele was more frequent in patients with femoral atherosclerotic calcification. They concluded that the $-7 \mathrm{~A}$ or Ala 83 alleles of the MGP gene may confer an increased risk of plaque calcification and myocardial infarction [26]. Brancaccio et al. found that the -138 TT genotype was more frequent in hemodialysis patients and the -7 AA genotype was more frequent in both chronic kidney disease and hemodialysis patients when compared with control group. They suggested that patients with -7A allele had an increased risk of calcification and cardiovascular events [27].

Cassidy-Bushrow reported that the MGP Thr83Ala polymorphism was associated with CAC progression [28]. Garbuzova et al. compared 115 acute coronary syndrome (ACS) patients with 115 healthy subjects in their study and they revealed that a polymorphism of MGP G-7A was significantly associated with ACS. However, they did not find any significant relation between ACS and T-138C and Thr83Ala [29]. Najafi et al. showed in their study that the MGP promoter polymorphic variants (MGP promoter rs 1800801 G-7A, rs1800802 T-138C and rs1800799 polymorphisms) and its serum levels were not associated with the stenosis of coronary arteries [30].

In this study, we aimed to establish the relationship between the distributions of nucleotide alterations found in promoter and coding regions of the MGP gene in patients with CAD. According to the literature CAC is more prevalent in patients 
with older age, DM, and hypertension. In this study, the patient group was older than the control group; and DM and hypertension were more prevalent in patient group. However, there was no significant difference between the patient and control group. In these patients, the vessel calcification may be related to other molecular activated pathways including passive calcium deposition.

\section{Study Limitations}

The population of the study was relatively small. This was a limitation of the study. Furthermore, larger studies are needed to investigate the relationship between MGP gene polymorphism and CAD.

In conclusion, in this study, we investigated the relationship between MGP gene polymorphism and CAD. However, according to our findings, there was no statistically significant difference between the $\mathrm{CAD}$ and the control group.

Conflict of Interest: The authors declare no conflict of interest.

Financial Disclosure: No financial support was received.

Acknowledgement: We are grateful to Dicle University DUBAP for their sponsorship about this study and English editing of this manuscript.

\section{REFERENCES}

1. Ross R. Atherosclerosis--an inflammatory disease. N Engl J Med 1999;340:115-126.

2. Mintz GS, Popma JJ, Pichard AD, et al.Patterns of calcification in coronary artery disease. A statistical analysis of intravascular ultrasound and coronary angiography in 1155 lesions. Circulation 1995;91:19591965.

3. Watson KE. Pathophysiology of coronary calcification. J Cardiovasc Risk 2000;7:93-97.

4. Wexler L, Brundage B, Crouse J, et al. Coronary artery calcification: pathophysiology, epidemiology, imaging methods, and clinical implications. A statement for health professionals from the American Heart Association. Writing Group. Circulation 1996;94:1175-1192.

5. Rumberger JA, Simons DB, Fitzpatrick LA, Sheedy PF, Schwartz RS. Coronary artery calcium area by electron-beam computed tomography and coronary atherosclerotic plaque area. A histopathologic correlative study. Circulation 1995;92:2157-2162.

6. Doherty TM, Detrano RC. Coronary arterial calcification as an active process: a new perspective on an old problem. Calcif Tissue Int 1994;54:224-230.

7. Blacher J, Guerin AP, Pannier B, Marchais SJ, London GM. Arterial calcifications, arterial stiffness, and cardiovascular risk in end-stage renal disease. Hypertension 2001;38:938-942.

8. London GM, Guerin AP, Marchais SJ, Metivier F, Pannier B, Adda H. Arterial media calcification in end-stage renal disease: impact on allcause and cardiovascular mortality. Nephrol Dial Transplant 2003;18:1731-1740.

9. Proudfoot D, Shanahan CM. Biology of calcification in vascular cells: intima versus media. Herz 2001;26:245-251.

10. Kurabayashi M. Vascular Calcification - Pathological Mechanism and Clinical Application - . Role of vascular smooth muscle cells in vascular calcification. Clin Calcium 2015;25:661-669.
11. Proudfoot D, Skepper JN, Shanahan CM, Weissberg PL. Calcification of human vascular cells in vitro is correlated with high levels of matrix Gla protein and low levels of osteopontin expression. Arterioscler Thromb Vasc Biol 1998;18:379-388.

12. Cancela L, Hsieh CL, Francke U, Price PA. Molecular structure, chromosome assignment, and promoter organization of the human matrix Gla protein gene. J Biol Chem 1990;265:15040-15048.

13. Worcester EM. Inhibitors of stone formation. Semin Nephrol 1996;16:474-486.

14. Miller SA, Dykes DD, Polesky HF. A simple salting out procedure for extracting DNA from human nucleated cells. Nucleic Acids Res $1988 ; 16: 1215$.

15. Napoli C, Glass CK, Witztum JL, Deutsch R, D'Armiento FP, Palinski W. Influence of maternal hypercholesterolaemia during pregnancy on progression of early atherosclerotic lesions in childhood: Fate of Early Lesions in Children (FELIC) study. Lancet 1999;354:1234-1241.

16. Gassett AJ, Sheppard L, McClelland RL,et al. Risk Factors for LongTerm Coronary Artery Calcium Progression in the Multi-Ethnic Study of Atherosclerosis. J Am Heart Assoc 2015;4(8).

17. Raggi P, Callister TQ, Shaw LJ. Progression of coronary artery calcium and risk of first myocardial infarction in patients receiving cholesterollowering therapy. Arterioscler Thromb Vasc Biol 2004;24:1272-1277.

18. Schurgers LJ, Cranenburg EC, Vermeer C. Matrix Gla-protein: the calcification inhibitor in need of vitamin K. J Thromb Haemost 2008;100:593-603.

19. Price PA, Williamson MK, Haba T, Dell RB, Jee WS. Excessive mineralization with growth plate closure in rats on chronic warfarin treatment. Proc Natl Acad Sci USA 1982;79:7734-7738.

20. Howe AM, Webster WS. The warfarin embryopathy: a rat model showing maxillonasal hypoplasia and other skeletal disturbances. Teratology 1992;46:379-390.

21. Hale JE, Fraser JD, Price PA. The identification of matrix Gla protein in cartilage. J Biol Chem 1988;263:5820-5824.

22. Luo G, Ducy P, McKee MD, et al. Spontaneous calcification of arteries and cartilage in mice lacking matrix GLA protein. Nature 1997;386:7881.

23. Sweatt A, Sane DC, Hutson SM, Wallin R. Matrix Gla protein (MGP) and bone morphogenetic protein- 2 in aortic calcified lesions of aging rats. J Thromb Haemost 2003;1:178-185.

24. Huang H, Virmani R, Younis H, Burke AP, Kamm RD, Lee RT. The impact of calcification on the biomechanical stability of atherosclerotic plaques. Circulation 2001;103:1051-1056.

25. Farzaneh-Far A, Davies JD, Braam LA, et al. A polymorphism of the human matrix gamma-carboxyglutamic acid protein promoter alters binding of an activating protein-1 complex and is associated with altered transcription and serum levels. J Biol Chem 2001;276:32466-32473.

26. Herrmann SM, Whatling C, Brand E, et al. Polymorphisms of the human matrix gla protein (MGP) gene, vascular calcification, and myocardial infarction. Arterioscler Thromb Vasc Biol 2000;20:2386-2393.

27. Brancaccio D, Biondi ML, Gallieni M, et al. Matrix GLA protein gene polymorphisms: clinical correlates and cardiovascular mortality in chronic kidney disease patients. Am J Nephrol 2005;25:548-552.

28. Cassidy-Bushrow AE, Bielak LF, Levin AM, et al. Matrix gla protein gene polymorphism is associated with increased coronary artery calcification progression. Arterioscler Thromb Vasc Biol 2013;33:645651.

29. Garbuzova VY, Gurianova VL, Stroy DA, Dosenko VE, Parkhomenko AN, Ataman AV. Association of matrix Gla protein gene allelic polymorphisms (G(-7)-->A, T(-138)-->C and Thr(83)-->Ala) with acute coronary syndrome in the Ukrainian population. Exp Clin Cardiol 2012;17:30-33. 
30. Najafi M, Roustazadeh A, Amirfarhangi A, Kazemi B. Matrix Gla protein (MGP) promoter polymorphic variants and its serum level in stenosis of coronary artery. Mol Biol Rep 2014;41:1779-1786. 